\title{
Associational resistance and associational susceptibility Specialist herbivores show contrasting responses to tree stand diversification
}

\author{
Journal Article \\ Author(s): \\ Plath, Mirco; Dorn, Silvia; Riedel, Judith; Barrios, Hector; Mody, Karsten \\ Publication date: \\ 2012-06 \\ Permanent link: \\ https://doi.org/10.3929/ethz-b-000048937 \\ Rights / license: \\ In Copyright - Non-Commercial Use Permitted \\ Originally published in: \\ Oecologia 169(2), https://doi.org/10.1007/s00442-011-2215-6
}




\title{
Associational resistance and associational susceptibility: specialist herbivores show contrasting responses to tree stand diversification
}

\author{
Mirco Plath · Silvia Dorn · Judith Riedel • \\ Hector Barrios $\cdot$ Karsten Mody
}

Received: 6 April 2011 / Accepted: 22 November 2011/Published online: 9 December 2011

(C) Springer-Verlag 2011

\begin{abstract}
Heterospecific neighbors may reduce damage to a focal plant by lowering specialist herbivore loads (associational resistance hypothesis), or enhance damage by increasing generalist herbivore loads (associational susceptibility hypothesis). We tested the associational effects of tree diversity on herbivory patterns of the tropical focal tree Tabebuia rosea in an experimental plantation setup, which contained tree monocultures and mixed stands. We found higher herbivore damage to $T$. rosea at higher tree diversity, indicating that $T$. rosea did not benefit from associational resistance but rather experienced associational susceptibility. The specific consideration of the two dominant insect herbivore species of $T$. rosea, the specialist chrysomelid Walterianella inscripta and the specialist pyralid Eulepte gastralis, facilitated understanding of the detected damage patterns. Tree diversity exerted opposite effects on tree infestation by the two herbivores. These findings point to resource concentration effects for the chrysomelid beetle (favored by tree monoculture) and to resource dilution effects for the pyralid caterpillar (favored by tree mixture) as underlying mechanisms of
\end{abstract}

Communicated by Andreas Prinzing.

Electronic supplementary material The online version of this article (doi:10.1007/s00442-011-2215-6) contains supplementary material, which is available to authorized users.

M. Plath $\cdot$ S. Dorn $\cdot$ J. Riedel $\cdot$ K. Mody $(\bowtie)$

Institute of Agricultural Sciences, Applied Entomology,

ETH Zurich, Schmelzbergstrasse 9/LFO, 8092 Zurich,

Switzerland

e-mail: karsten.mody@ipw.agrl.ethz.ch

H. Barrios

Entomology Master Program, University of Panama,

Panama City, Republic of Panama herbivore distribution. A strong contribution of the pyralid to overall damage patterns in diversified stands suggests that associational susceptibility may not necessarily be related to higher abundances of generalist herbivores but may also result from specialized herbivores affected by resource dilution effects. Thus, the identity and biology of herbivore species has to be taken into account when attempting to predict damage patterns in forest ecosystems.

Keywords Competitor-free space - Diet breadth - Insect herbivory $\cdot$ Pasture reforestation - Tree diversity

\section{Introduction}

Vegetation complexity and characteristics of neighboring plants may strongly affect interactions between herbivores and a focal host plant, and specific associations can either decrease or increase the susceptibility of plants to herbivores (Agrawal et al. 2006; Lewinsohn and Roslin 2008; Barbosa et al. 2009). Derived from these observations, the 'associational resistance hypothesis' predicts that a plant, in addition to its specific morphological and chemical defense traits (Coley and Barone 1996; Schoonhoven et al. 2005; Gutbrodt et al. 2011), might experience 'associational resistance' to herbivores by growing in close proximity to other plant species (Tahvanainen and Root 1972). Several factors may contribute to associational resistance, including chemical and physical interference of neighboring plant species as well as greater abundances and diversity of natural enemies (Hambäck and Beckerman 2003). In particular, host density is predicted to have strong effects on specialist herbivores as formulated in the resource concentration hypothesis (Root 1973). This hypothesis states that specialist herbivore loads increase 
with higher densities of the host plant in a given area unit, as specialist herbivores may locate their host plant more easily and stay longer in patches with high host plant densities.

In contrast, the 'associational susceptibility hypothesis' predicts that plants in diverse stands may suffer more from herbivore attack than plants in single-species stands (Brown and Ewel 1987). This phenomenon is expected to occur when the principal pests are generalist herbivores (Jactel and Brockerhoff 2007), which benefit from the broader diet range available in diverse plant communities (Unsicker et al. 2008). Associational susceptibility may also occur when the focal plant is a less-preferred host growing in close proximity to a highly preferred host (Atsatt and O'Dowd 1976), which allows a spill-over of generalist herbivores after depletion of the favored host plant (White and Whitham 2000).

Information concerning the effects of stand diversification on insect pests mainly stems from agricultural systems (Andow 1991; Tscharntke et al. 2005). The existing studies accounting for forest systems reveal contrasting results, demonstrating that mixed stands can suffer lower, higher, or similar pest damage compared to single-species stands (Koricheva et al. 2006; Jactel and Brockerhoff 2007; Kaitaniemi et al. 2007; Vehvilainen et al. 2007; Plath et al. 2011b). Reflecting the opposite predictions of the hypotheses on 'associational resistance' and 'associational susceptibility', these equivocal results emphasize that the net effects of diversification in forest systems may only be understood when the spatial arrangement of the focal plant and characteristics of the principal herbivores are studied in concert. Hence, the identification of the key herbivores responsible for the damage, their level of host plant specialization, and the relative proportions of damage they cause may improve our understanding of the mechanisms that govern the direction of resource and associational effects on herbivore-plant interactions in forest systems.

Information on the biology of insect pests in forest systems can help to disentangle the causes of insect pest outbreaks, and hence, to improve the delivery of forest ecosystem services (Hambäck and Beckerman 2003; Butler et al. 2007; Tylianakis et al. 2007). Such information is particularly required for Central America, where forest plantations with native tree species are increasingly considered as an eligible strategy to mitigate the negative impacts of deforestation and land degradation (Lamb et al. 2005; Brockerhoff et al. 2008; Hall et al. 2011). However, although insect pests frequently impede the successful establishment of forest plantations, the key insect species associated with tree species native to Central America are virtually unidentified to date (FAO 2009). To protect trees from expected herbivore attacks, landholders often resort to broad-spectrum pesticides (Garen et al. 2009), but until now there is little evidence for the effectiveness of these products under prevailing field conditions. The widespread notion that forest monocultures are susceptible to insect pest attacks has promoted the consideration of stand diversification as sustainable, biodiversity-oriented strategy to control key insect pests in forestry systems (Lamb et al. 2005; Koricheva et al. 2006 and references therein). However, the effects of heterospecific tree associations on infestation of a focal host tree by key herbivores have rarely been compared to effects of monocultures or to conventional protection by insecticides.

In the present study, we examined the effects of tree stand diversification on leaf herbivory (associational effects) of a focal native timber tree, Tabebuia rosea Bertol. (Bignoniaceae), growing in monoculture and in threespecies mixtures in an experimental plantation setup in Panama. Insecticide application was used in additional treatments to achieve baseline information on reduction of herbivore damage through conventional protection measures. We concurrently identified the principal herbivore for each stand type, determined its level of host plant specialization and assessed the effect of individual stand types on the herbivores' densities (resource effects) and on related herbivore impact on $T$. rosea.

According to the described resource-related associational effects on specialist and generalist herbivores, we expected to identify one or several specialist herbivores as key herbivores in the monocultures. The specialist herbivores were expected to accumulate in higher densities in monocultures compared to mixed stands. We further expected to identify one or several generalist key herbivores in mixed-species stands, occurring in higher densities in mixed stands compared to monocultures. We hypothesized that specialist key herbivores contribute most to overall damage of $T$. rosea in monocultures, and that generalist herbivores are responsible for principal damage in mixed plantings.

Specifically, we addressed the following questions: (1) Does tree stand diversification affect herbivory of $T$. rosea? (2) Does the identity of key herbivores and their level of host specialization differ among stand types? (3) Do different stand types affect the densities of the specific key herbivores and their contribution to herbivory of $T$. rosea?

\section{Materials and methods}

Study site and planting design

Three tree species native to Central America were planted in an experimental planting system on former pasture in Sardinilla, Province Colon, Central Panama $\left(9^{\circ} 19^{\prime} 30^{\prime \prime} \mathrm{N}\right.$, $79^{\circ} 38^{\prime} 00^{\prime \prime} \mathrm{W}$, elevation around $70 \mathrm{~m}$ a.s.l.) in August 2006 
(for details on study site, see Plath et al. 2011a). The selected tree species were Tabebuia rosea, Anacardium excelsum (Bertero and Balb. ex Kunth) Skeels (Anacardiaceae) and Cedrela odorata L. (Meliaceae). The three tree species co-occur in natural Panamanian forest ecosystems (Croat 1978), and are of regional economical importance because of their suitability for reforestation activities and as valuable timber (ITTO 2006; Wishnie et al. 2007; Van Breugel et al. 2011).

Potted seedlings of each tree species were raised in a PRORENA (Proyecto de Reforestación con Especies Nativas) nursery for 3 months before being planted on the pasture. To support tree establishment, $15 \mathrm{~g}$ of 12-72$12 \mathrm{~N}-\mathrm{P}-\mathrm{K}$ granular fertilizer was applied at the time of planting to the bottom of each planting hole and covered with soil before planting, and again 2 months after planting to each seedling on the soil surface. Concomitant vegetation in the plots was trimmed with machetes to $10 \mathrm{~cm}$ height every 3 months during the rainy season (average vegetation height across plots before cutting $21 \pm 5 \mathrm{~cm}$ ) to allow for unconstrained localization of the host trees by insect herbivores (average tree height across plots at study onset: $T$. rosea $84 \pm 2 \mathrm{~cm}, A$. excelsum $55 \pm 2 \mathrm{~cm}$, C. odorata $46 \pm 1 \mathrm{~cm})$.

Seedlings of $T$. rosea, A. excelsum and $C$. odorata were planted in stands of 36 trees, using a standardized $6 \times 6$ Latin square design with a planting distance of $2 \mathrm{~m}$. Tree individuals were arranged in five planting schemes: (1-3) monocultures for all three timber species, (4) 3-species mixed stands, and (5) 3-species mixed stands protected by the insecticide cypermethrin (pyrethroid, Arribo EC 20 or 6 EC, $1.2 \mathrm{~g} / 1$ spray solution; applied biweekly to the foliage) and the insecticide/nematicide carbofuran (carbamate, Furadan $10 \mathrm{GR}, 5-25 \mathrm{~g} /$ tree depending on the effective canopy area; applied bimonthly to the soil). The five planting schemes were arranged at one locality, which defined a coherent plot. This plot was replicated five times at different locations across the study site.

\section{Insect survey}

Insect counts were conducted for all timber trees on a biweekly basis from April 2007 (year 1) to April 2008 (year 2). No survey was conducted at the end of December of year 1 and in the middle of February of year 2. Insect abundance was assessed by a visual census of all insects on a tree's trunk and every leaf during day and night within a 24-h period. Detected individuals of adult Coleoptera and of larval Lepidoptera were assigned to morphospecies, which were deposited in a reference collection created on the basis of previous survey samplings. Individuals of species sampled for the first time, or individuals not immediately assignable to a morphospecies, were collected, preserved in $70 \%$ ethanol, and allocated to the reference collection.

The sequence of planting schemes surveyed within each plot was changed randomly. All 36 trees were sampled in the unprotected mixed and in the insecticide-protected mixed stands (12 individuals per tree species). In the monoculture stands, surveys were carried out on 12 trees for each timber species, which were randomly selected before starting the insect assessments. To obtain planting positions comparable to the mixed stands, six trees from the edge and six trees from the inner area were investigated. The same tree individuals were surveyed during the whole study period. According to this sampling scheme, a total of 540 trees were surveyed at the beginning of the investigation, with 60 trees per species in each of the three planting schemes containing a particular tree species. The number of surveyed trees declined over time as a consequence of tree mortality $(T$. rosea $=1.5 \%$, A. excelsum $=30.4 \%, \quad$ C. odorata $=54.1 \%$ ), which was not affected by planting schemes or herbivore impact (Plath et al. 2011b). Final analyses included all trees that survived until the end of the sampling period.

Identification of key herbivores and their feeding specialization

Key herbivores were defined as the most abundant herbivore species found for each unprotected planting scheme on the focal host tree $T$. rosea. Species identification relied on comparisons of the collected morphospecies with reference collections at Panamanian institutions (Fairchild Museum, University of Panama, Smithsonian Tropical Research Institute), and on consultation with experts for the respective taxonomic groups. Key herbivores were confirmed to feed on $T$. rosea by determining their acceptance of $T$. rosea in no-choice feeding experiments. Feeding tests were conducted by offering leaf discs (18 $\mathrm{mm}$ diameter) of one young and one mature leaf of the same tree individual in a Petri dish $(90 \mathrm{~mm}$ diameter; inlaid with a moistened filter paper) to single individuals of the key herbivore species for $24 \mathrm{~h}$. Leaf discs were replaced $12 \mathrm{~h}$ after initiation of the test with fresh discs from another tree individual. Each herbivore individual (i.e. adult Coleoptera or larval Lepidoptera) was exclusively used for a single feeding test.

As a measure of specialization, we determined the acceptance of the two remaining study tree species (A. excelsum and $C$. odorata) and of two tree species occurring across the study site in the vicinity of the experimental tree stands (Gliricidia sepium (Jacq.) Kunth ex Walp (Fabaceae) and Guazuma ulmifolia Lam. (Sterculiaceae)) by the key herbivores. The studied trees belong to five phylogenetically distant plant families in four plant 
orders (T. rosea: Scrophulariales; A. excelsum, C. odorata: Sapindales; G. sepium: Fabales; G. ulmifolia: Malvales). In the context of our study, we classified the key herbivores as specialist herbivores of $T$. rosea when (1) they exclusively fed on $T$. rosea leaves and rejected to feed on any of the four other tree species, and (2) more than $95 \%$ of all recorded individuals were found on $T$. rosea. In comparison, we categorized herbivores as generalists when they fed on two or more of the five tree species (see also Basset et al. 1996; Novotny et al. 2002; Unsicker et al. 2006). We used this definition of specialization to assess whether the herbivores may profit from our specific tree stand diversification design by a broadened diet range, which may apply for species using at least two of the study trees but not for species restricted to $T$. rosea.

\section{Leaf herbivory}

Leaf damage was measured at the end of the growing season in December of year 1 and reassessed in December of year 3 (2009). In year 1, the first 15 fully developed leaves in the top foliage layer were selected from each T. rosea individual and damage was quantified for the complete mature leaves (separated into five leaflets), which were characterized by dark green color and high toughness compared to soft young leaves. In total, 1,862 leaves were analyzed (monocultures: $n=642$; unprotected mixed stands: $n=625$; insecticide-protected mixed stands: $n=595$ ), with an average of 10.8 leaves per tree individual. No significant differences in the number of analyzed leaves per tree were found among the individual stand types (Kruskal-Wallis: $H_{2,172}=1.39, P>0.05$ ). Leaves were photographed with a digital camera (Panasonic, Lumix DMC-LZ3) without removal from trees using a standardized, established procedure (Mody and Linsenmair 2004). Leaves were spread out on a gray-colored plastic board, covered with a hinged lid of transparent, nonreflecting glass, and photographed from a fixed distance, without flash and with a consistent resolution in the shade of a tarpaulin. For high-throughput quantitative analysis of leaf damage, digital photographs were analyzed using a custom-built software tool (Plath et al. 2011b). Individual leaf damage was calculated as the percent leaf area removed from the total leaf area by herbivores, including leaf fragments discolored due to herbivore feeding (for details, see Plath et al. 2011b). Reassessment of leaf damage in year 3 was conducted for $60 T$. rosea individuals (average tree height $339 \pm 13 \mathrm{~cm}$ ), selected by randomly choosing six trees from each monoculture and unprotected mixed stand per plot. From each selected tree, ten leaves were haphazardly collected, and leaf damage was determined for the fourth leaflet of all mature leaves (five to ten mature leaves, average 7.5 leaves per tree; damage to the fourth leaflet was found to be representative for damage to all five leaflets, J. Riedel unpublished data). Leaflets were photographed with a digital camera (Canon Powershot A630) as described above, with the exception that leaves had been removed from the tree and photographing took place in the laboratory. Digital photographs were analyzed using the graphics package Adobe Photoshop (v.12.0.4). Leaf damage was quantified by referring to the pixel number of reference areas, which were photographed together with the leaves. The missing parts of the leaflets were accordingly determined, after outlining them in the photograph. The percentage area removed by herbivores was computed from missing and total leaf area. In both year 1 and year 3 , values of individual leaf damage were averaged for every tree. Leaves that were completely eaten or dropped after herbivore damage were not considered.

To estimate the contribution of key herbivore groups to total leaf damage, each leaf was screened for prevailing damage types, which were small-hole feeding by chrysomelids (Fig. 1a) and large-scale skeletonization by

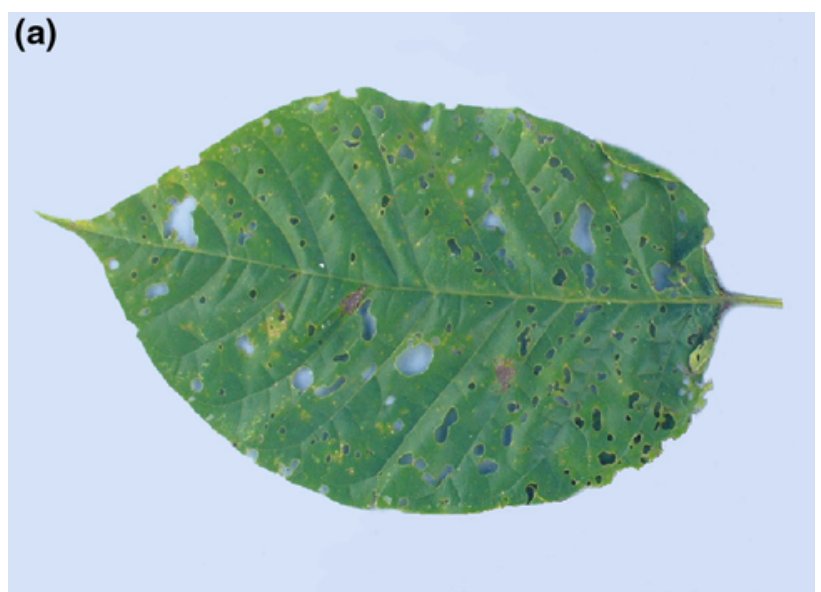

(b)

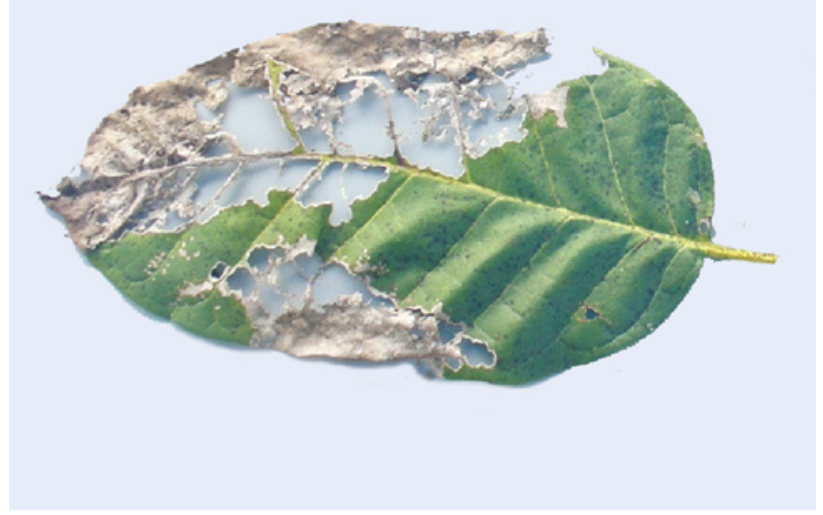

Fig. 1 Symptoms of damage by a the chrysomelid beetle Walterianella inscripta and $\mathbf{b}$ the pyralid caterpillar Eulepte gastralis on leaflets of Tabebuia rosea 
lepidopteran larvae (Fig. 1b), in year 1. The contribution of each damage type to total damage was then assessed by assigning the percent damaged leaf area that each type contributed to total damaged leaf area to 1 of 7 categories: $0=$ no contribution, $1=1-20 \%, \quad 2=21-40 \%, \quad 3=41-60 \%$, $4=61-80 \%, 5=81-99 \%, 6=100 \%$ contribution to total damage. Damage that could not be assigned to either damage type was considered as a third type of damage (i.e. 'damage by other herbivores'). The proportion of leaf damage attributed to each damage type was averaged for each studied tree.

Data analysis

Herbivore damage was arcsin-transformed to account for non-normal or heteroscedastic error terms in the analyses. The number of individuals of each key herbivore was calculated for each tree individual and survey event, using the average insect number found in day and night samples to consider possible double counts of less mobile herbivores such as caterpillars. As a measure of tree infestation by the key herbivores, herbivore density was assessed as the total individual number per tree found in all surveys until mid-December of year 1 , divided by the respective total leaf number at that time. Leaf counts considered mature and fully expanded young leaves. Herbivore density was log-transformed after adding 0.01 to each value to retain zero counts in the analysis (Zuur et al. 2009).

The effects of planting schemes on herbivore damage were assessed using linear mixed effect models with herbivore damage and herbivore densities, respectively, as response variables, planting schemes as fixed factors and plot as a random factor, accounting for the nesting of planting schemes within plots. The effect of planting schemes on herbivore densities was tested in two stages. First, the effect of insecticide application was analyzed by comparing infested (density $>0$ ) and non-infested tree individuals (density $=0$ ) for the three planting schemes to consider the zero-inflated count data within the insecticide-protected mixed stands. Binomial data were analyzed in a generalized linear mixed effect model using penalized quasi-likelihood. Second, the effects of stand diversification (monocultures vs. unprotected mixed stands) on herbivore density were subsequently analyzed using a linear mixed effect model. To evaluate the potential impact of tree architecture on herbivore densities, tree height (measured at the end of the growing season in December of year 1) was used as a covariate. False discovery rate control was applied for multiple tests following linear mixed effect models (Verhoeven et al. 2005). Pearson correlation analyses were conducted to test the relationship between tree height and herbivore densities of the identified key herbivores as well as between herbivore densities and overall herbivore damage in each planting scheme. The relationship between overall leaf damage and key herbivore density was assessed by Spearman rank correlation analyses. Correlation analyses included all trees that survived until the end of the study period in the individual planting schemes (monocultures: $n=59$; unprotected mixed stands: $n=60$; insecticide-protected mixed stands: $n=59$ ). The effect of tree mortality (i.e. decreased tree density) on herbivore densities in the individual planting schemes was tested with Pearson correlations, relating the total number of living tree individuals (i.e. $T$. rosea individuals in monocultures with $n=33-36$, and individuals of all three timber species in the unprotected mixed stands with $n=22-32$ ) to the respective mean herbivore densities for each planting scheme and plot at the end of the growing season in December of year 1 (see Electronic Supplementary Material 1). The effects of planting schemes on the contribution of the key herbivores to total herbivore damage were compared using Kruskal-Wallis tests followed by Dunn's post hoc tests.

Linear mixed effect models were performed using $\mathrm{R}$ 2.13.0 (2011; The R Foundation for Statistical Computing). Non-parametric post hoc tests were computed with SsS 1.1a (1998; Rubisoftware, Eichenau, Germany). All remaining statistical analyses were conducted with SPSS 19.0.0 for Mac OS X (2010; IBM SPSS Statistics, Chicago, IL, USA). For clarity, all figures show untransformed data.

\section{Results}

\section{Identification of key herbivores}

We identified two key herbivores, which were numerically dominant on $T$. rosea across the unprotected planting schemes: the chrysomelid beetle Walterianella inscripta Jacoby ( $n=2,209$ adult individuals; no larvae occurred on the shoot system of $T$. rosea) and the pyralid caterpillar Eulepte gastralis Guenée ( $n=2,036)$, representing 36.8\% of all beetles and $88.9 \%$ of all caterpillars observed during all surveys on the three timber species. The total abundances of $W$. inscripta and E. gastralis significantly differed between the timber species ( $W$. inscripta: $\chi^{2}(2)=$ 6,450.0, $P<0.001 ;$ E. gastralis: $\chi^{2}(2)=6,090.0, P<$ 0.001 ), and specimens of both herbivore species were almost exclusively found on $T$. rosea (W. inscripta $\geq 98.7 \%$; E. gastralis $\geq 99.9 \%$ ). Both W. inscripta and E. gastralis were classified as specialist herbivores of $T$. rosea according to the given definition (see "Materials and methods"). All tested individuals of either herbivore (W. inscripta: $n=15 ;$ E. gastralis: $n=14$ per tree species) that showed feeding activity ( $n=13$ for each species) fed exclusively on $T$. rosea.

Across all individual stand types, total individual numbers of W. inscripta and E. gastralis exceeded individual 
numbers of the third most abundant herbivore species that was found and confirmed to feed on T. rosea by factors of 8 and 9 , respectively. This third-ranked species was another chrysomelid of the genus Walterianella $(n=245)$. W. inscripta was the most abundant herbivore species in the monocultures $(n=1,629)$, exhibiting three times higher individual numbers than $E$. gastralis $(n=556)$, the second most abundant herbivore in this planting scheme. In contrast, E. gastralis was the most abundant herbivore in the unprotected mixed stands $(n=1,432)$, where $W$. inscripta was the second most abundant herbivore $(n=473)$. In the protected stands, both herbivores were rare (W. inscripta: $n=107 ;$ E. gastralis: $n=48$ ).

Both $W$. inscripta and E. gastralis showed a strong temporal variation in abundance. Either species was rare at the beginning of the rainy season (total $n<10$ individuals). Abundance of $W$. inscripta peaked in the middle of the rainy season (September/October), and then gradually decreased until complete disappearance in the dry season (January). Abundance of E. gastralis peaked in October and again in January of the following year. Subsequently, E. gastralis was found in low numbers until the end of the study period (see also Electronic Supplementary Material 2).

\section{Tree infestation}

The number of tree individuals infested by W. inscripta or E. gastralis was significantly different among planting schemes (W. inscripta: $F_{2,8}=14.86, P=0.002 ;$ E. gastralis: $F_{2,8}=29.19, P<0.001$ ) (see also Electronic Supplementary Material 3). It was significantly lower in the insecticide-protected mixed stands (W. inscripta: $n=24 ; E$. gastralis: $n=4$ ) than in the monocultures (W. inscripta: $n=55$, $P=0.001 ;$ E. gastralis: $n=48, P<0.001)$ and in the unprotected mixed stands ( $W$. inscripta: $n=48, P=0.005$; E. gastralis: $n=55, P<0.001)$. The number of infested trees was not different for monocultures and unprotected mixed stands for either herbivore species $(P>0.05)$.

Densities of $W$. inscripta and E. gastralis on T. rosea were significantly different among monocultures and unprotected mixed stands. For W. inscripta, density was significantly higher in the monocultures than in the unprotected mixed stands $\left(F_{1,4}=12.60, \quad P=0.024\right)$ (Fig. 2a; see also Electronic Supplementary Material 4). Tree height strongly influenced the densities of $W$. inscripta $\left(F_{1,108}=10.55, P=0.002\right)$. Tree height was positively correlated to the densities of $W$. inscripta in the monocultures $(R=0.36, P=0.005)$ and in the unprotected mixed stands $(R=0.36, P=0.005)$. In contrast, density of $E$. gastralis was significantly higher in the unprotected mixed stands than in the monocultures $\left(F_{1,4}=8.49, P=0.044\right)$ (Fig. $2 \mathrm{~b}$; see also Electronic

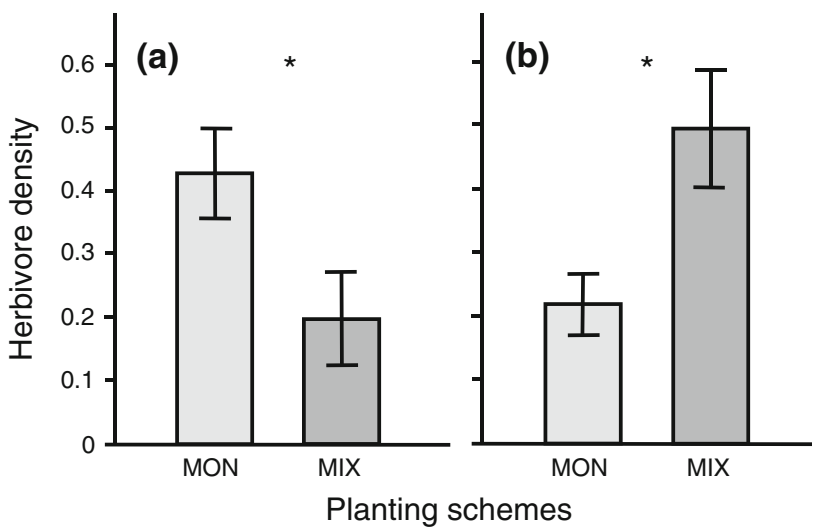

Fig. 2 Densities (mean \pm SE) of a Walterianella inscripta beetles and $\mathbf{b}$ Eulepte gastralis caterpillars on the host tree Tabebuia rosea growing in monocultures (MON), and in 3-species mixed stands (MIX). Densities were calculated as total number of individuals per leaf for either herbivore. Tree number per planting scheme: MON $=59$, MIX $=60$. Linear mixed effect model, $* P<0.05$

Supplementary Material 4). Tree height had no significant influence on the density of E. gastralis $\left(F_{1,108}=0.06\right.$, $P=0.809)$. Tree mortality showed no significant correlation with the density of either herbivore in the monocultures (W. inscripta: $R=-0.422, P=0.479 ;$ E. gastralis: $R=0.242, P=0.695)$ or in the unprotected mixed stands (W. inscripta: $R=-0.060, P=0.924 ; \quad E$. gastralis: $R=0.378, P=0.530$ ).

Leaf herbivory and contribution of herbivore species to damage patterns

Leaf damage to $T$. rosea was significantly affected by planting schemes in year 1 and year 3 (year $1: F_{2,8}=61.38$, $P<0.001$; year 3: $F_{1,4}=9.27, P=0.038$ ) (Fig. 3). In year 1 , damage was significantly higher in the unprotected mixed stands than in the monocultures $(P=0.037)$. Damage was lowest in the insecticide-protected mixed stands, which differed significantly from the monocultures and from the unprotected mixed stands (for both $P<0.001$ ) (Fig. 3a). Similarly to year 1 , leaf damage in year 3 was significantly higher in the unprotected mixed stands than in the monocultures ( $P=0.038$, see above) (Fig. 3b).

The prevailing damage types on $T$. rosea leaves, smallhole feeding damage and large-scale skeletonization, were assigned to $W$. inscripta and to E. gastralis, respectively, as only very few individuals of comparable hole-feeders or other potential skeletonizers were observed during the whole study (see above: "Identification of key herbivores"; and M. Plath, personal observation). An analysis based on this classification revealed that both herbivores significantly contributed to herbivory, but to different extents in the individual stand types. The contribution of $W$. inscripta 


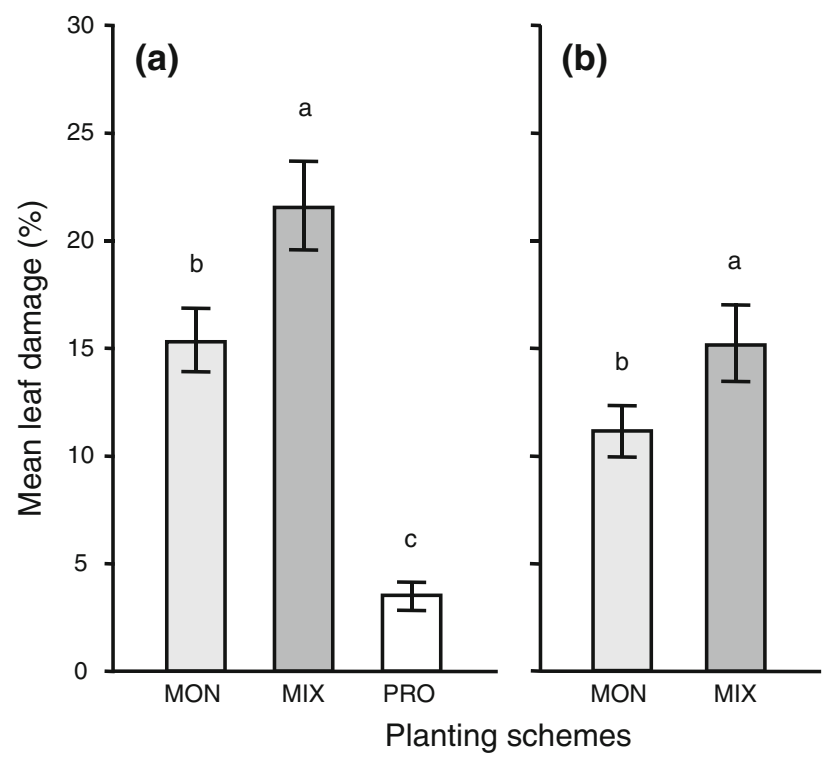

Fig. 3 Herbivore damage (mean \pm SE) of mature leaves of Tabebuia rosea at the end of the growth period in December of a year 1 and b year 3. Saplings of $T$. rosea were planted in monocultures (MON), in 3-species mixed stands (MIX), or in 3-species mixed stands protected by insecticides (PRO). Contrasting letters above bars refer to significant differences among conspecific trees growing in different planting schemes (after false discovery rate control of pairwise comparisons in (a); linear mixed effect model, $P<0.05)$. Number of analyzed leaves per planting scheme: year 1: $\mathrm{MON}=642$, $\mathrm{MIX}=625, \mathrm{PRO}=595$; year $3: \mathrm{MON}=219, \mathrm{MIX}=198 . \mathrm{PRO}$ exclusively assessed for year 1

to overall leaf damage was significantly different between the three planting schemes $\left(H_{2,175}=70.10, P<0.001\right)$. It was significantly higher in the monocultures than in the mixed stands $(Q=2.77, P<0.05)$ (Fig. 4a). In the insecticide-protected mixed stands, leaf damage inflicted by $W$. inscripta was significantly lower than in the monocultures $(Q=8.23, P<0.05)$ and in the unprotected mixed stands $(Q=5.36, P<0.05)$. Correspondingly, overall leaf damage was positively correlated with the density of $W$. inscripta in the monocultures $\left(R_{s}=0.30\right.$, $P=0.024)$. No significant correlation was found in the unprotected $\left(R_{S}=0.10, P=0.450\right)$ and in the protected mixed stands $\left(R_{s}=-0.10, P=0.461\right)$. The contribution of $E$. gastralis to overall leaf damage also differed significantly between the three planting schemes $\left(H_{2,175}=\right.$ $78.94, P<0.001)$. In contrast to damage by $W$. inscripta, it was significantly higher in the unprotected mixed stands than in the monocultures $(Q=3.85, P<0.05)$ (Fig. 4b). In the insecticide-protected mixed stands, leaf damage inflicted by $E$. gastralis was significantly lower than in the monocultures $(Q=5.02, P<0.05)$ and in the unprotected mixed stands $(Q=8.85, P<0.05)$. Correspondingly, overall leaf damage in the unprotected mixed stands was positively correlated with the density of $E$. gastralis $\left(R_{s}=0.41, P<0.001\right)$, whereas no such correlation was

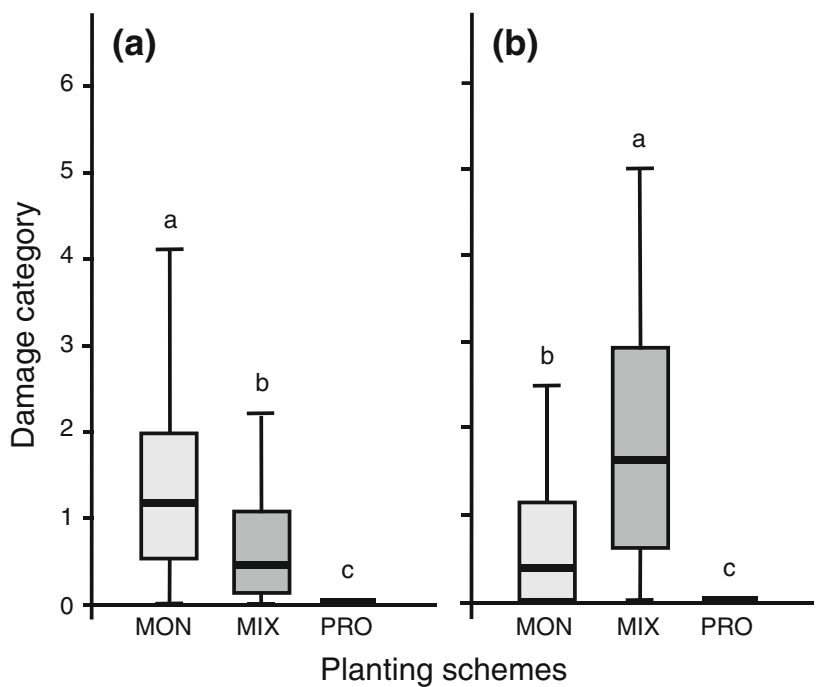

Fig. 4 Average contribution of a Walterianella inscripta beetles and b Eulepte gastralis caterpillars to total damage of mature leaves of the host tree Tabebuia rosea growing in monocultures (MON), in 3-species mixed stands (MIX), or in 3-species mixed stands protected by insecticides (PRO). Herbivore damage was measured in categories: $0=$ no contribution, $1=1-20 \%, \quad 2=21-40 \%, \quad 3=41-60 \%$, $4=61-80 \%, 5=81-99 \%, 6=100 \%$ contribution to total damage. Box-whisker plots show minimum, first quartile, median, third quartile and maximum. Outliers and extreme values are not shown for clarity. Contrasting letters above box-plots refer to significant differences among the three planting schemes (Kruskal-Wallis test, Dunn's post hoc test, $P<0.05)$. Number of analyzed leaves per planting scheme: $\mathrm{MON}=642, \mathrm{MIX}=625, \mathrm{PRO}=595$

found in the monocultures $\left(R_{s}=0.11, P=0.410\right)$ and in the protected mixed stands $\left(R_{s}=0.19, P=0.161\right)$.

\section{Discussion}

Host tree association significantly affected herbivore damage as well as the densities and impact of key herbivores on the tropical timber tree $T$. rosea in an experimental plantation setup on degraded pasture. Two findings shed new light on ecological hypotheses. First, contrary to the 'resource concentration hypothesis', we found that certain specialist herbivores may respond positively to resource dilution and accumulate on host trees growing in heterospecific stands rather than in conspecific stands. Second, contrary to the 'associational susceptibility hypothesis', higher herbivore damage to a focal host tree in heterospecific stands compared to conspecific stands is not necessarily related to generalist herbivores. In fact, it may substantially depend on a single or few specialist herbivores.

The finding that overall herbivore damage was higher in mixed stands than in monocultures indicates that $T$. rosea did not benefit from associational resistance but rather experienced associational susceptibility at higher tree 
diversity. This result contradicts reports from other systems, where a decrease in herbivory was noted with increasing plant diversity both for herbs (Andow 1991; Unsicker et al. 2006) and for trees (Jactel and Brockerhoff 2007; Kaitaniemi et al. 2007; Sobek et al. 2009). Many studies attribute high herbivore damage in monocultures to specialist herbivores and consider resource concentration effects (Root 1973) as an explanation for the detected herbivory patterns (see reviews of Andow 1991; Jactel et al. 2005). The resource concentration hypothesis predicts that specialist herbivores accumulate in large and dense patches of host plants and that, in turn, damage by specialist herbivores decreases with increasing plant diversity.

However, a positive relationship between tree diversity and herbivore damage as found in our study was also reported in some recent studies on herbivore-tree interactions (Vehvilainen et al. 2007; Schuldt et al. 2010). In these studies, the positive relationship between tree diversity and herbivore damage was assumed to reflect an increased impact of generalist herbivores, which exceeds the impact of specialist herbivores in monocultures as predicted by the hypothesis of 'associational susceptibility' (White and Whitham 2000; see also Jactel and Brockerhoff 2007). Referring to these assumptions, and considering the herbivory patterns found in our study, the higher herbivore damage in the (unprotected) mixed stands was expected to reflect an increased impact of generalist herbivores, counterbalancing the impact of specialist herbivores in the monocultures.

Our results showed that herbivory in the monocultures was mediated by the specialist chrysomelid beetle $W$. inscripta, confirming the expectation that monocultures are favoring specialists. However, contrary to expectations, herbivory in the unprotected mixed stands was not mainly affected by generalist herbivores, but was predominantly influenced by another specialist, the pyralid caterpillar E. gastralis. Hence, higher tree diversity may not necessarily reduce specialist infestation, but can even promote host plant colonization and related damage by specialized herbivores (Yamamura and Yano 1999; but see Sholes 2008; Otway et al. 2005). The strong contribution of E. gastralis to overall damage in the mixed stands demonstrates that associational susceptibility is not necessarily related to higher abundances of generalist herbivores but can substantially depend on one (or more) specialized herbivores. Thus, the direction of associational effects is strongly governed by the specific herbivore responsible for the damage, as W. inscripta and E. gastralis differed crucially in their species-specific responses to the spatial arrangement of the focal host tree, leading to their opposite impacts on $T$. rosea within the different stand types.

Density of $W$. inscripta on $T$. rosea, and accordingly the contribution to leaf damage by the beetle, was highest in the monocultures and it was relatively low at higher tree diversity (i.e. in unprotected mixed stands), following the predictions of the resource concentration hypothesis. The close proximity of unrelated tree species to $T$. rosea in the mixed stands may have influenced colonization of $T$. rosea by $W$. inscripta by physically and/or chemically masking the focal host species (Agrawal et al. 2006; Barbosa et al. 2009). In contrast to mixed stands, the accumulation of $T$. rosea in monocultures provides not only a higher resource quantity but may also enhance the beetle's opportunity to switch between host tree individuals to attain higher quality food by 'intraspecific dietary mixing' (Mody et al. 2007). These factors likely led to a reduced emigration rate and, consequently, to an aggregated herbivore distribution within the monoculture stands. A preference of $W$. inscripta for taller tree individuals was indicated by the positive correlation between tree height and beetle density. Faster growing tree individuals may invest more resources into growth and may hence be less defended than slower growing conspecifics (Herms and Mattson 1992; Dobbertin 2005). The highly mobile $W$. inscripta may actively choose and aggregate on such less defended individuals. However, the factors decisively determining host tree choice need further investigation as information on the biology of $W$. inscripta is so far lacking. In fact, the present study appears to be the first that identifies $W$. inscripta as a key herbivore on $T$. rosea in tropical afforestation systems.

In contrast to $W$. inscripta, density and impact of E. gastralis on $T$. rosea was positively related to tree diversity. This finding contradicts the resource concentration hypothesis, and indicates that tree diversity affected the distribution patterns of $E$. gastralis via a resource dilution effect (Yamamura 2002; Otway et al. 2005). As E. gastralis caterpillars complete development on the same tree individual on which oviposition occurs (Hernández and Briceño 1999), their distribution on host tree individuals is expected to strongly depend on the host location and oviposition behavior of the adult female moth (Root and Kareiva 1984; Stoeckli et al. 2008). Our results suggest that ovipositing females of E. gastralis prefer tree individuals growing in heterospecific stands, irrespective of their height. Previous studies on other lepidopteran species suggest that such selective behavior may enhance the probability for successful development and survival of the offspring (Hern et al. 1996; Doak et al. 2006; Bonebrake et al. 2010). By selecting host trees in the mixed stands, and therefore more isolated hosts compared to the monocultures, the female $E$. gastralis moth may search for 'competitor-free space', thereby accessing resources for their offspring that are less exploited by other herbivores such as $W$. inscripta (Root and Kareiva 1984; see also Fisher et al. 2000; Tack et al. 2009 for intraguild competition for resources). 
Avoidance of oviposition in monocultures by E. gastralis moths may also represent a search for 'enemy-free space' (Pöykkö 2011 and references therein), as a more complex vegetation and larger distances between host tree individuals can impede host localization by key enemies of a focal herbivore (Gols and Harvey 2009; Randlkofer et al. 2010; Mody et al. 2011). As herbivore egg numbers or effects of antagonists on immature stages were not quantified in our study, we cannot exclude the possibility that the lower density of $E$. gastralis caterpillars observed in monocultures may also be related to higher rates of predation or parasitism in this stand type (Gingras et al. 2003; Randlkofer et al. 2010). The potential of natural enemies to reduce $E$. gastralis populations is indicated by a study from a Venezuelan forest reserve, which states that the abundance of this important herbivore of $T$. rosea is generally kept at low levels by parasitoids and predators (Hernández and Briceño 1998; Hernández and Briceño 1999).

The finding that generalist herbivores were not abundant in the mixed stands was surprising, particularly when considering coleopterans. A comprehensive study by Novotny et al. (2010) on host specialization of tropical forest insect herbivores revealed that the dominating adult leaf chewers (such as beetles) on a specific plant species are generalists, whereas larval leaf chewers were rather found to be specialists. However, tree diversity and structural heterogeneity in our plantation were low compared to natural forests, possibly leading to low numbers of generalist herbivores. This explanation is supported, for example, by observations from a subtropical forest in China, indicating that increased plant diversity is related to increased herbivory by polyphagous herbivores (Schuldt et al. 2010).

Levels of herbivore leaf damage in unprotected mixed stands in our study amounted to 22 and $15 \%$ at 1 and 3 years after establishment, respectively. These values are high compared to available data from various tree species in natural tropical ecosystems and also compared to previous results from $T$. rosea in plantations. They indicate that $T$. rosea may experience comparably high insect damage when growing in tree plantations, at least when associated with the "wrong" neighbors (Barbosa et al. 2009). Leaf damage in tropical forests ranged from $11 \%$ for shade tolerant to $14 \%$ for tropical dry forest trees in a meta-study comprising many different tree species (Coley and Barone 1996), and in savannas from 15 to nearly $0 \%$ across 25 adult-size tree species in Brazil (Marquis et al. 2001) and from 9 to $3 \%$ across 9 tree species from the sapling-stage size class in Ivory Coast (Unsicker and Mody 2005). Previous studies reporting herbivore damage specifically for $T$. rosea grown in Panamanian plantations may have underestimated herbivory, with $3 \%$ leaf damage in 1-yearold monocultures (Paul et al. 2011) and 9\% in unprotected 2-year-old mixed stands (Plath et al. 2011b). Both studies quantified damage earlier in the season than the current study, which is the first to assess the key herbivores and their temporal abundance patterns (see Electronic Supplementary Material 2 for temporal abundance patterns). In fact, both key herbivores reach their maximum abundance in the late rainy season, rendering their full contribution to damage only observable at this later point in time.

From an applied point of view, our results emphasize that consideration of key herbivores and of their speciesspecific responses to management strategies may crucially enhance the establishment of new tree plantations. Compared to monocultures, mixed stands are regarded as a strategy to reduce negative impacts of insect herbivores in plantation forestry (Wagner et al. 1996; Montagnini and Jordan 2005; Kelty 2006). Our results, however, indicate that this assumption is not unequivocally true. The contrasting responses of the two key herbivores to individual stand types point to a possible trade-off even when specialist herbivores dominate, as each unprotected stand type favored another key herbivore. The low infestation and reduced damage of $T$. rosea in the insecticide-protected mixed stands suggest that the application of insecticides may represent a possible measure supporting the establishment of high-value timber species. This assumption is supported by findings from a study in the same experimental plots (Plath et al. 2011b) revealing that growth of $T$. rosea saplings was significantly higher in the insecticide-protected stands than in the unprotected monocultures and mixed stands. However, successful tree protection by insecticides often depends on the herbivore species (e.g., Newton et al. 1993 and Wylie 2001 for chemical control of the pyralid moth Hypsipyla spp.), and on specific smallscale environmental conditions (Plath et al. 2011b). Moreover, application of insecticides can have detrimental effects on natural enemies of herbivores (Pedigo and Rice 2009). Thus, insecticides cannot be regarded as a miracle cure solving all herbivore-related obstacles in tropical plantation establishment.

\section{Conclusions}

Our results reveal that stand diversification can lead to opposite responses of key herbivores of tropical tree plantations. By considering the individual key herbivore species, we were able to explain the seemingly contradictory coexistence of associational resistance and of associational susceptibility to specialist herbivores. Because tree diversity is regarded as an important tool for sustainable pest management in tree plantations, it is important to explicitly consider the dominant herbivore species as well as their biology and responses to the spatial arrangement of 
host and non-host trees during the plantation establishment process. Considering species-specific herbivore traits can enhance our understanding of so far neglected associational effects (i.e. associational susceptibility mediated by specialist herbivores), and may help to disentangle the causes of insect outbreaks, to develop sustainable forest management strategies, and to improve the delivery of forest ecosystem services.

Acknowledgments We thank Catherine Potvin for access to the Sardinilla site, the Smithsonian Tropical Research Institute for administration and logistics, as well as José Monteza and Sardinilla personnel for assistance with fieldwork. The Panamanian National Environmental Authority (ANAM) granted the required permits. We thank Wolfgang Einhäuser-Treyer (Philipps-University Marburg), and the Machine Learning Laboratory (ETH Zurich) for development of the leaf herbivory software; Konrad Fiedler (University of Vienna) and David Furth (Smithsonian Natural History Museum, Washington) for help with insect identification; Jake Alexander, Jana Collatz and Bettina Gutbrodt for useful comments on the manuscript. This study has been supported by a grant of the ETH North-South Centre to S.D and K.M.

\section{References}

Agrawal AA, Lau JA, Hambäck PA (2006) Community heterogeneity and the evolution of interactions between plants and insect herbivores. Q Rev Biol 81:349-376

Andow DA (1991) Vegetational diversity and arthropod population response. Annu Rev Entomol 36:561-586

Atsatt PR, O' Dowd DJ (1976) Plant defense guilds. Science 193:24-29

Barbosa P, Hines J, Kaplan I, Martinson H, Szczepaniec A, Szendrei Z (2009) Associational resistance and associational susceptibility: having right or wrong neighbors. Annu Rev Ecol Evol Syst 40:1-20

Basset Y, Samuelson GA, Allison A, Miller SE (1996) How many species of host-specific insects feed on a species of tropical tree? Biol J Linn Soc 59:201-216

Bonebrake TC, Boggs CL, McNally JM, Ranganathan J, Ehrlich PR (2010) Oviposition behavior and offspring performance in herbivorous insects: consequences of climatic and habitat heterogeneity. Oikos 119:927-934

Brockerhoff EG, Jactel H, Parrotta JA, Quine CP, Sayer J (2008) Plantation forests and biodiversity: oxymoron or opportunity? Biodivers Conserv 17:925-951

Brown BJ, Ewel JJ (1987) Herbivory in complex and simple tropical successional ecosystems. Ecology 68:108-116

Butler SJ, Vickery JA, Norris K (2007) Farmland biodiversity and the footprint of agriculture. Science 315:381-384

Coley PD, Barone JA (1996) Herbivory and plant defenses in tropical forests. Annu Rev Ecol Syst 27:305-335

Croat TB (1978) Flora of Barro Colorado Island. Stanford University Press, Stanford

Doak P, Kareiva P, Kingsolver J (2006) Fitness consequences of choosy oviposition for a time-limited butterfly. Ecology 87:395408

Dobbertin M (2005) Tree growth as indicator of tree vitality and of tree reaction to environmental stress: a review. Eur J For Res $124: 319-333$

FAO (2009) Global review of forest pests and diseases. FAO, Rome
Fisher AEI, Hartley SE, Young M (2000) Direct and indirect competitive effects of foliage feeding guilds on the performance of the birch leaf-miner Eriocrania. J Anim Ecol 69:165-176

Garen EJ, Saltonstall K, Slusser JL, Mathias S, Ashton MS, Hall JS (2009) An evaluation of farmers' experiences planting native trees in rural Panama: implications for reforestation with native species in agricultural landscapes. Agrofor Syst 76:219-236

Gingras D, Dutilleul P, Boivin G (2003) Effect of plant structure on host finding capacity of lepidopterous pests of crucifers by two Trichogramma parasitoids. Biol Control 27:25-31

Gols R, Harvey JA (2009) Plant-mediated effects in the Brassicaceae on the performance and behaviour of parasitoids. Phytochem Rev 8:187-206

Gutbrodt B, Mody K, Dorn S (2011) Drought changes plant chemistry and causes contrasting responses in lepidopteran herbivores. Oikos 120:1732-1740

Hall JS, Ashton MS, Garen EJ, Jose S (2011) The ecology and ecosystem services of native trees: implications for reforestation and land restoration in Mesoamerica. For Ecol Manag 261:15531557

Hambäck PA, Beckerman AP (2003) Herbivory and plant resource competition: a review of two interacting interactions. Oikos 101:26-37

Herms DA, Mattson WJ (1992) The dilemma of plants: to grow or defend. Q Rev Biol 67:283-335

Hern A, EdwardsJones G, McKinlay RG (1996) A review of the preoviposition behaviour of the small cabbage white butterfly, Pieris rapae (Lepidoptera: Pieridae). Ann Appl Biol 128:349_ 371

Hernández G, Briceño A (1998) Factores bióticos y abióticos que favorecen el desarollo de Eulepte gastralis (GN.), en vivero de Apamate. Rev For Venez 42:157-166

Hernández G, Briceño A (1999) Ciclo de vida del gusano esqueletizador Eulepte gastralis (GN.) (Lepidoptera: Pyralidae), del Apamate (Tabebuia rosea (Bertol), DC.). Rev For Venez 43:4352

ITTO (2006) Status of tropical forest management 2005. International Tropical Timber Organization, Yokohama

Jactel H, Brockerhoff EG (2007) Tree diversity reduces herbivory by forest insects. Ecol Lett 10:835-848

Jactel H, Brockerhoff E, Duelli P (2005) A test of the biodiversitystability theory: meta-analysis of tree species diversity effects on insect pest infestations, and re-examination of responsible factors. In: Scherer-Lorenzen M, Körner C, Schulze ED (eds) Forest diversity and function: temperate and boreal systems. Springer, Berlin, pp 236-262

Kaitaniemi P, Riihimaki J, Koricheva J, Vehvilainen H (2007) Experimental evidence for associational resistance against the European pine sawfly in mixed tree stands. Silva Fenn 41:259_ 268

Kelty MJ (2006) The role of species mixtures in plantation forestry. For Ecol Manag 233:195-204

Koricheva J, Vehvilainen H, Riihimaki J, Ruohomaki K, Kaitaniemi P, Ranta H (2006) Diversification of tree stands as a means to manage pests and diseases in boreal forests: myth or reality? Can J For Res 36:324-336

Lamb D, Erskine PD, Parrotta JA (2005) Restoration of degraded tropical forest landscapes. Science 310:1628-1632

Lewinsohn TM, Roslin T (2008) Four ways towards tropical herbivore megadiversity. Ecol Lett 11:398-416

Marquis RJ, Diniz IR, Morais HC (2001) Patterns and correlates of interspecific variation in foliar insect herbivory and pathogen attack in Brazilian cerrado. J Trop Ecol 17:127-148

Mody K, Linsenmair KE (2004) Plant-attracted ants affect arthropod community structure but not necessarily herbivory. Ecol Entomol 29:217-225 
Mody K, Unsicker SB, Linsenmair KE (2007) Fitness related dietmixing by intraspecific host-plant-switching of specialist insect herbivores. Ecology 88:1012-1020

Mody K, Spoerndli C, Dorn S (2011) Within-orchard variability of the ecosystem service 'parasitism': effects of cultivars, ants and tree location. Basic Appl Ecol 12:456-465

Montagnini F, Jordan CF (2005) Tropical forest ecology: the basis for conservation and management. Springer, Berlin

Newton AC, Baker P, Ramnarine S, Mesen JF, Leakey RRB (1993) The mahogany shoot borer: prospects for control. For Ecol Manag 57:301-328

Novotny V, Basset Y, Miller SE, Drozd P, Cizek L (2002) Host specialization of leaf-chewing insects in a New Guinea rainforest. J Anim Ecol 71:400-412

Novotny V et al (2010) Guild-specific patterns of species richness and host specialization in plant-herbivore food webs from a tropical forest. J Anim Ecol 79:1193-1203

Otway SJ, Hector A, Lawton JH (2005) Resource dilution effects on specialist insect herbivores in a grassland biodiversity experiment. J Anim Ecol 74:234-240

Paul GS, Montagnini F, Berlyn GP, Craven DJ, Van Breugel M, Hall JS (2011) Foliar herbivory and leaf traits of five native tree species in a young plantation of Central Panama. New Forests. doi:10.1007/s11056-011-9267-7

Pedigo LP, Rice ME (2009) Entomology and pest management, 6th edn. Pearson Prentice Hall, Upper Saddle River, NJ

Plath M, Mody K, Potvin C, Dorn S (2011a) Do multipurpose companion trees affect high value timber trees in a silvopastoral plantation system? Agrofor Syst 81:79-92

Plath M, Mody K, Potvin C, Dorn S (2011b) Establishment of native tropical timber trees in monoculture and mixed-species plantations: small-scale effects on tree performance and insect herbivory. For Ecol Manag 261:741-750

Pöykkö H (2011) Enemy-free space and the host range of a lichenivorous moth: a field experiment. Oikos 120:564-569

Randlkofer B, Obermaier E, Hilker M, Meiners T (2010) Vegetation complexity: the influence of plant species diversity and plant structures on plant chemical complexity and arthropods. Basic Appl Ecol 11:383-395

Root RB (1973) Organization of a plant-arthropod association in simple and diverse habitats: the fauna of collards (Brassica oleracea). Ecol Monogr 43:95-124

Root RB, Kareiva PM (1984) The search for resources by cabbage butterflies (Pieris rapae): ecological consequences and adaptive significance of markovian movements in a patchy environment. Ecology 65:147-165

Schoonhoven LM, JJAv Loon, Dicke M (2005) Insect-plant biology, 2nd edn. Oxord University Press, New York

Schuldt A et al (2010) Tree diversity promotes insect herbivory in subtropical forests of south-east China. J Ecol 98:917-926

Sholes ODV (2008) Effects of associational resistance and host density on woodland insect herbivores. J Anim Ecol 77:16-23

Sobek S, Scherber C, Steffan-Dewenter I, Tscharntke T (2009) Sapling herbivory, invertebrate herbivores and predators across a natural tree diversity gradient in Germany's largest connected deciduous forest. Oecologia 160:279-288

Stoeckli S, Mody K, Dorn S (2008) Influence of canopy aspect and height on codling moth (Lepidoptera: Tortricidae) larval infestation in apple, and relationship between infestation and fruit size. J Econ Entomol 101:81-89
Tack AJM, Ovaskainen O, Harrison PJ, Roslin T (2009) Competition as a structuring force in leaf miner communities. Oikos 118:809-818

Tahvanainen JO, Root RB (1972) The influence of vegetational diversity on the population ecology of a specialized herbivore, Phyllotreta cruciferae (Coleoptera: Chrysomelidae). Oecologia 10:321-346

Tscharntke T, Klein AM, Kruess A, Steffan-Dewenter I, Thies C (2005) Landscape perspectives on agricultural intensification and biodiversity: ecosystem service management. Ecol Lett 8:857-874

Tylianakis JM, Tscharntke T, Lewis OT (2007) Habitat modification alters the structure of tropical host-parasitoid food webs. Nature 445:202-205

Unsicker SB, Mody K (2005) Influence of tree species and compass bearing on insect folivory of nine common tree species in the West African savanna. J Trop Ecol 21:227-231

Unsicker SB, Baer N, Kahmen A, Wagner M, Buchmann N, Weisser WW (2006) Invertebrate herbivory along a gradient of plant species diversity in extensively managed grasslands. Oecologia 150:233-246

Unsicker SB, Oswald A, Kohler G, Weisser WW (2008) Complementarity effects through dietary mixing enhance the performance of a generalist insect herbivore. Oecologia 156:313-324

Van Breugel $\mathrm{M}$ et al (2011) Early growth and survival of 49 tropical tree species across sites differing in soil fertility and rainfall in Panama. For Ecol Manag 261:1580-1589

Vehvilainen H, Koricheva J, Ruohomaki K (2007) Tree species diversity influences herbivore abundance and damage: metaanalysis of long-term forest experiments. Oecologia 152:287-298

Verhoeven KJF, Simonsen KL, McIntyre LM (2005) Implementing false discovery rate control: increasing your power. Oikos 108:643647

Wagner MR, Cobbinah JR, Ofori DA (1996) Companion planting of the nitrogen-fixing Gliricidia sepium with the tropical timber species Milicia excelsa and its impact on the gall forming insect Phytolyma lata. In: Mattson WJ, Niemela P, Rousi M (eds) International symposium on dynamics of forest herbivory: quest for pattern and principle. USDA For Serv Gen Tech Rep NC183. Maui, Hi, pp 264-271

White JA, Whitham TG (2000) Associational susceptibility of cottonwood to a box elder herbivore. Ecology 81:1795-1803

Wishnie $\mathrm{MH}$ et al (2007) Initial performance and reforestation potential of 24 tropical tree species planted across a precipitation gradient in the Republic of Panama. For Ecol Manag 243:39-49

Wylie FR (2001) Control of Hypsipyla spp. shoot borers with chemical pesticides: a review. In: Floyd RB, Hauxwell C (eds) Hypsipyla shoot borers in Meliaceae. Australian Centre for International Agricultural Research, Canberra, pp 109-115

Yamamura K (2002) Biodiversity and stability of herbivore populations: influences of the spatial sparseness of food plants. Popul Ecol 44:33-40

Yamamura K, Yano E (1999) Effects of plant density on the survival rate of cabbage pests. Res Popul Ecol 41:183-188

Zuur AF, Ieno EN, Walker N, Saveliev AA, Smith GM (2009) Mixed effects models and extensions in ecology with R: statistics for biology and health. Springer, New York 